\title{
Determinación del potencial promotor del crecimiento vegetal de las enterobacterias aisladas de la rizósfera del cultivo de maíz (Zea mays L.)
}

\section{Determination of plant growth promoting potential of enterobacteria isolated from the rhizosphere of maize (Zea mays L.)}

\author{
Luis H. León Mendoza* \\ Facultad de Ciencias Biológicas, Universidad Nacional Pedro Ruiz Gallo, Av. Juan XXIII 391, Lambayeque, Perú.
}

Recibido 22 septiembre 2014. Aceptado 24 noviembre 2014.

\begin{abstract}
Resumen
El maíz amarillo duro es el tercer cultivo en importancia en el Perú y forma parte de la cadena maízavicultura-porcicultura, de impacto significativo en la actividad económica y social nacional, sin embargo, en el 2011, solo el 40\% del maíz ofertado correspondió a la producción nacional. En busca de alternativas para disminuir el uso de fertilizantes químicos se realizan investigaciones con denominadas rizobacterias promotoras del crecimiento vegetal. Las bacterias se aislaron de la rizósfera de maíz procedentes de campos agrícolas de los distritos de Monsefú y Reque, Región Lambayeque. Se realizó una dilución en solución salina esterilizada: $0,87 \% \mathrm{NaCl}$, p/v y se sembró en agar Mac Conkey, incubando a $30^{\circ} \mathrm{C}$ por 48 horas. Se obtuvieron 269 cultivos puros de bacterias, se investigó su reacción bioquímica en agar Hierro Triple Azúcar, agar Hierro Lisina, agar Citrato de Simons, caldo peptonado, caldo rojo de metilo Voges-Proskauer y caldo nitrato, identificándose $66 \%$ como enterobacterias de los géneros Pantoea (49\%), Klebsiella (17\%), Kluyvera (16\%), Serratia (11\%), Citrobacter (4\%) y Hafnia (3\%). Con las enterobacterias nativas se cuantificó hasta 31,67 ppm de nitrógeno fijado como amonio; 54,25 ppm de ácido indol acético y 4,78 ppm de fósforo solubilizado, así como también se determinó actividad proteolítica, quitinolítica y antagónica a Fusarium verticillioides. El $16 \%$ de enterobacterias nativas no afectó la emergencia de maíz amarillo duro hibrido simple AGRI- 144, el $77 \%$ la afectó positivamente y el $7 \%$ la afectó negativamente. A su vez, ninguna bacteria afectó la sobrevivencia. Se demostró el potencial promotor del crecimiento vegetal de las enterobacterias aisladas de campos de cultivos de la Región de Lambayeque.
\end{abstract}

Palabras clave: Maíz, enterobacterias, fertilizante, promotora, crecimiento.

\begin{abstract}
The yellow maize is the third most important crop in Peru and part of the chain maize-poultry-pig, significant impact on the national economic and social activity, however, in 2011, only $40 \%$ of the corn offered corresponded to the domestic industry. Looking for alternatives to reduce the use of chemical fertilizers, have performed investigations with plant growth promoting rhizobacteria. Bacteria were isolated from the rhizosphere of maize from districts Monsefú and Reque, Lambayeque. Dilution was made into sterile saline $0.87 \% \mathrm{NaCl} w / \mathrm{v}$ and plated on MacConkey agar, incubating at $30^{\circ} \mathrm{C}$ for 48 hours. 269 pure cultures of bacteria were obtained, the biochemical reaction was investigated in agar Triple sugar iron agar Iron Lysine, agar Citrate Simons, peptone broth, red broth methyl Voges-Proskauer and nitrate broth, was identified 66\% as Enterobacteriaceae of genera Pantoea (49\%), Klebsiella (17\%), Kluyvera (16\%), Serratia (11\%), Citrobacter (4\%) and Hafnia (3\%). The native enterobacteria were quantified to $31.67 \mathrm{ppm}$ of fixed nitrogen as ammonia; $54.25 \mathrm{ppm}$ indole acetic acid and 4,78 ppm solubilized phosphorus, activity proteolytic and chitinolytic and antagonistic activity of Fusarium verticillioides were also determined. $16 \%$ of native enterobacteria did not affect the emergence of hard yellow maize, $77 \%$ affected positively and $7 \%$ affected negatively. In turn, none bacteria affected survival. Was demonstrated the potential plant growth promoter of enterobacteria isolated from field crops in the region of Lambayeque.
\end{abstract}

Keywords: Corn, enterobacteria, fertilizer, promoting, growth.

\footnotetext{
* Autor para correspondencia

E-mail: leonmendoza9@gmail.com (L. León).
} 


\section{Introducción}

Los fertilizantes químicos representan 20 - 30\% de los costos de producción de un cultivo y cuando son correctamente utilizados incrementan la productividad y rentabilidad; sin embargo, cada año se incrementa la cantidad de fertilizantes por aplicar, debido a la menor eficiencia de adsorción en el suelo y absorción por la planta. Según la Asociación Internacional de la Industria de Fertilizantes entre 1996 a 2008, el consumo se incrementó en $31 \%$ en el mundo y $56 \%$ en los países en vías de desarrollo, así como también el precio de algunos fertilizantes se triplicó, disminuyendo la rentabilidad del cultivo (Nicolalde y Quintana, 2010). En la búsqueda de alternativas para disminuir el uso de fertilizantes químicos se realizan investigaciones con las denominadas rizobacterias promotoras del crecimiento de las plantas (Plant growth promoting rhizobacteria, PGPR). Estas bacterias de vida libre, asociadas a las raíces, cerca o incluso en el interior de los tejidos, estimulan los ciclos biogeoquímicos de los nutrientes, fijan nitrógeno atmosférico de una manera no simbiótica, solubilizan fosfatos, producen reguladores del crecimiento y sideróforos, así como, también reduce el ataque de microorganismos patógenos e insectos. Las PGPR a menudo incrementan la superficie de raíz, con el consecuente aumento de la absorción de nutrientes y la producción de la planta. (Bashan et al., 1996; Kloepper, 2003; Bhattacharyya y Jha, 2012). Ensayos realizados con diversas PGPR en diferentes suelos, regiones climáticas $\mathrm{y}$ cultivos de importancia agronómica demostraron $5 \%$ a $30 \%$ de incremento en el rendimiento, así como, la disminución de $25 \%$ a $50 \%$ de la dosis del fertilizante químico (Aguado y Moreno, 2008; Adesemoye et al., 2009; García et al., 2012); sin embargo, también se han reportado resultados contradictorios en los que no se ha obtenido la respuesta positiva esperada, posiblemente porque los microorganismos no se adaptaron a las condiciones del suelo, muy diferentes a las de su procedencia, no compitieron exitosamente con la biota nativa o no fueron capaces de sobrevivir en condiciones desfavorables (Díaz et al., 2001).

En Lambayeque, se practica la agricultura en diversos suelos y condiciones climáticas. Es posible que en la rizósfera de los cultivos de maíz se encuentren enterobacterias que poseen características $\mathrm{y}$ propiedades como promotoras del crecimiento de plantas; sin embargo, en la actualidad no se han realizado estudios para aislarlas, caracterizarlas y posteriormente determinar su efecto en los cultivos agrícolas. Por lo expuesto, se planteó la siguiente investigación, teniendo como objetivos aislar e identificar enterobacterias de la rizósfera de cultivos de maíz, Zea mays L. de campos agrícolas en los distritos de Monsefú y Reque, en Lambayeque; determinar in vitro el potencial biológico de las enterobacterias nativas como productoras de enzimas y ácido indolacético, fijadoras de nitrógeno, solubilizadoras de fósforo, antagonistas de Fusarium verticilliodes, así como también determinar el efecto en la emergencia y sobrevivencia de maíz amarillo duro híbrido simple en condiciones de invernadero.

\section{Materiales y métodos Diseño Metodológico}

Se utilizó un diseño transeccional descriptivo (Hernández et al., 2003) para indagar la incidencia y los valores que manifestaron las variables dentro de un enfoque cuantitativo. El procedimiento consistió en medir las propiedades de las variables y proporcionar su descripción; teniendo como variables cuantitativas las enterobacterias productoras de enzimas, ácido indol acético, fijadoras de nitrógeno, solubilizadoras de fósforo y antagonistas del hongo Fusarium verticillioides. El trabajo de investigación se ejecutó en dos fases. En la primera fase, se realizó el aislamiento, detección, selección de 
enterobacterias nativas y su potencial como promotoras del crecimiento vegetal. La segunda fase, se determinó el porcentaje de emergencia y sobrevivencia en plántulas de maíz en invernadero.

\section{Muestreo}

Se colectaron 54 muestras de suelo rizosférico en 17 campos comerciales de maíz de los distritos de Monsefú y Reque en la Región Lambayeque, determinando la posición de los puntos de muestreo con un GPS GARMIN e Trex Vista HCx. Monsefú abarca 44,94 $\mathrm{km}^{2}$ y está comprendido entre los paralelos $6^{\circ} 52$ ' $30^{\prime \prime}$ de latitud sur y $79^{\circ} 52^{\prime} 09^{\prime \prime}$ longitud oeste, con un clima desértico subtropical árido. A su vez, el distrito de Reque tiene una superficie de $47,03 \mathrm{~km}^{2}$ y se ubica entre los paralelos 6 ${ }^{\circ} 52^{\prime} 00^{\prime \prime}$ latitud sur y 79 $49^{\prime} 27^{\prime \prime}$ longitud oeste, presentando un clima seco tropical (Municipalidad Distrital de Monsefú, 2013; Municipalidad Distrital de Reque, 2013). Las muestras se transportaron al Laboratorio de Microbiología y Parasitología sección de Biotecnología Microbiana de la facultad de Ciencias Biológicas en la Universidad Nacional Pedro Ruiz Gallo, Perú.

\section{Aislamiento de enterobacterias}

Para el aislamiento de enterobacterias, según la metodología mencionada por Cadena y Martínez (2011), cada muestra de suelo rizosférico fue deshidratada bajo sombra durante 72 horas y después fue triturada y tamizada. Del material obtenido se tomaron $10 \mathrm{~g}$ para realizar una dilución en $90 \mathrm{~mL}$ de solución salina esterilizada: $\mathrm{NaCl} 0,85 \%, \mathrm{p} / \mathrm{v}$. De esta dilución $10^{-1} \mathrm{se}$ extrajo una alícuota, se sembró mediante la técnica del agotamiento y estría en placas de Petri, con agar Mac Conkey y se incubó a $30^{\circ} \mathrm{C}$, por 48 horas. A continuación, se diferenciaron las colonias fermentadoras y no fermentadoras de lactosa y se cultivaron en agar tripticasa soya (TSA), a $30^{\circ} \mathrm{C}$, por 24 horas, para realizar las pruebas de oxidasa, catalasa y tinción de Gram. Después las colonias constituidas por bacilos Gram negativos, oxidasa negativos $\mathrm{y}$ catalasa positivas se guardaron en refrigeración a $8^{\circ} \mathrm{C}$. Para identificar los géneros de las bacterias nativas según Brenner et al. (2005) se investigó la fermentación de la glucosa, sacarosa y lactosa, así como la formación de gas y sulfuro de hidrógeno en agar Hierro Triple Azúcar: TSI, la descarboxilación de la lisina y producción de sulfuro de hidrógeno en agar Hierro Lisina: LIA, la utilización del citrato como fuente de carbono y energía en agar Citrato de Simons, la producción de indol en caldo peptonado, la formación de acidez a partir de la glucosa y producción de acetoina en caldo rojo de metilo Voges-Proskauer y la reducción de nitratos en caldo nitrato.

\section{Producción de enzimas}

Cada enterobacteria nativa fue sembrada por puntura superficial con el asa bacteriológica en anillo $(0,4 \mathrm{~cm}$ de diámetro) sobre agar leche $1 \%$ y agar quitina coloidal al $1 \%$ y fueron incubadas a $30^{\circ} \mathrm{C}$, por 48 y 120 horas, respectivamente, en aerobiosis, para la investigación de la actividad proteolítica Ríos y Zúñiga (2012) y quitinolítica (Franco, 2008). Con este propósito se observaron las colonias desarrolladas para detectar y medir el halo de hidrólisis o zona clara alrededor que evidenció la actividad proteolítica. A su vez, las bacterias que desarrollaron en agar quitina se consideraron con actividad quitinolítica.

\section{Detección y cuantificación de ácido indol acético (AIA) producido in vitro}

Para la detección y cuantificación de ácido indol acético según la reacción colorimétrica de Salkowski descrita por Mantilla (2007) y García y Muñoz (2010), cada bacteria nativa fue cultivada en $5 \mathrm{~mL}$ de caldo nutritivo por 24 horas, de donde se tomaron $0,6 \mathrm{~mL}$ para inocularlos en 5 $\mathrm{mL}$ de caldo tripticasa soya suplementado con triptófano. Después de la incubación a $30^{\circ} \mathrm{C}$, por 72 horas, en agitación constante (150 rpm), los cultivos fueron centrifu- 
gados a $3000 \mathrm{rpm}$, durante 5 minutos. A continuación $0,4 \mathrm{~mL}$ de cada uno de los sobrenadantes se depositaron en tubos, se agregaron $1,6 \mathrm{~mL}$ del reactivo de Salkowski modificado en una relación 1:4, se mezclaron y se dejaron en reposo durante 30 minutos, en oscuridad. La positividad a la producción de ácido indol acético estuvo dada por una coloración grosella y se leyó la absorbancia en espectrofotómetro de luz visible a $530 \mathrm{~nm}$. Las concentraciones se calcularon en una recta patrón que fue obtenida con diluciones sucesivas de una solución 100 ppm de ácido indol acético.

\section{Detección y cuantificación de nitrógeno fijado in vitro}

La detección de nitrógeno fijado in vitro según Cadena y Martínez (2011), cada bacteria fue sembrada por puntura en $6 \mathrm{~mL}$ de medio libre de nitrógeno con azul de bromotimol (Nfb) semisólido. La incubación se realizó en aerobiosis, a $30^{\circ} \mathrm{C}$, hasta por 1 semana y se consideraron como enterobacterias fijadoras de nitrógeno, aquellas donde se observó una película gruesa blanquecina entre 3 a $5 \mathrm{~mm}$ bajo la superficie del medio de cultivo y el viraje del indicador. La cuantificación de nitrógeno fijado in vitro según el método colorimétrico del fenolhipoclorito, descrito por Lara et al. (2007) y Cadena y Martínez (2011), cada bacteria nativa cultivada en agar nutritivo por 24 horas, fue inoculada en tubos de $15 \times 150 \mathrm{~mm}$ conteniendo 3 $\mathrm{mL}$ de caldo extracto de suelo y se incubaron a $30^{\circ} \mathrm{C}$, por 72 horas en agitación constante $(150 \mathrm{rpm})$. A continuación, se agregaron $9 \mathrm{~mL}$ de $\mathrm{KCl}$ $2 \mathrm{M}$, se agitaron a $150 \mathrm{rpm}$, durante 1 hora $\mathrm{y}$ se dejaron en reposo por 1 hora adicional, para después tomar $10 \mathrm{~mL}$ del sobrenadante y centrifugarlos (3000 rpm) durante 5 minutos. Luego, los sobrenadantes se vertieron en tubos de dilución, se añadieron $0,4 \mathrm{~mL}$ de solución alcohólica de fenol al 10\%; 0,4 mL de nitroprusiato de sodio al $0,5 \%$ y $1 \mathrm{~mL}$ de solución oxidante. Se agitaron para mezclar y después se dejaron en reposo durante 1 hora. La positividad a la fijación del nitrógeno in vitro estuvo dada por una coloración azul y se leyó la absorbancia en espectrofotómetro de luz visible, a 632,9 $\mathrm{nm}$. Las concentraciones de nitrógeno fijado como amonio, se calcularon en una recta patrón que fue obtenida con diluciones sucesivas de una solución de 100 ppm de cloruro de amonio.

\section{Detección y cuantificación de fósforo solubilizado in vitro}

La detección de fósforo solubilizado in vitro, se utilizó la metodología descrita por Vázquez et al. (2000). Cada bacteria fue sembrada por puntura superficial en agar para aislamiento de microorganismos solubilizadores de fósforo, Sundara Rao Sinha Medium, SRSM. Las placas de petri se incubaron a $30^{\circ} \mathrm{C}$, por 96 horas y las colonias solubilizadoras de fósforo fueron reconocidas por el cambio de color del indicador al amarillo y la formación de un halo traslúcido alrededor de la colonia. Después, las colonias se cultivaron nuevamente en agar SRSM, para verificar la actividad solubilizadora de fósforo y se midió el diámetro del halo de las colonias que conservaron su capacidad para solubilizar fósforo. Para la cuantificación del fósforo solubilizado, se obtuvo el inóculo de cada una de las bacterias solubilizadoras de fósforo cultivadas en 1 $\mathrm{mL}$ de caldo $\mathrm{SRSM}$ a $30^{\circ} \mathrm{C}$, durante 20 horas en agitación constante a $150 \mathrm{rpm}$. A continuación; $0,6 \mathrm{~mL}$ de cada uno de los cultivos bacterianos fueron inoculados en tubos con $6 \mathrm{~mL}$ de caldo SRSM e incubados a $30^{\circ} \mathrm{C}$, con agitación constante (150 rpm). Al momento de la inoculación (0 horas) y después de 72 horas, se tomaron submuestras de $3 \mathrm{~mL}$ de caldo SRSM que fueron centrifugados a 3000 rpm por 5 minutos y en el sobrenadante se cuantificó el fósforo soluble mediante el método colorimétrico del molibdato según Rodier y Rodi (2005). Los resultados se expresaron como fósforo solubilizado (ppm). 


\section{Prueba de antagonismo}

Se utilizó la técnica de enfrentamiento en "cultivo dual" (Fernández y Vega, 2001), según la cual cada bacteria nativa se sembró masivamente en uno de los cuatro extremos de una placa de petri con agar papa dextrosa (PDA), ocupando aproximadamente un cuarto del área total y se incubó a $30^{\circ} \mathrm{C}$, por 72 horas. A continuación, un fragmento $(0,9 \mathrm{~cm}$ de diámetro) del hongo $F$. verticillioides se depositó en el centro de las placas de petri a una distancia de $3 \mathrm{~cm}$ respecto a las enterobacterias. Después de 5 días de incubación a $30^{\circ} \mathrm{C}$, se midió el radio de la colonia del hongo y de la placa testigo. Para determinar si el crecimiento fúngico fue afectado por enterobacterias se aplicó la formula citada por Fernández y Vega (2001): \% inhibición $=((R T-R C) / R T) \times 100$; donde RT: Radio del Testigo de F. verticilloides sembrado en PDA; $R C$ : Radio de la colonia de F. verticilloides sembrado en PDA con enterobacterias nativas.

Los resultados se expresaron con porcentaje de inhibición del crecimiento respecto al testigo.

\section{Determinación de la emergencia y sobrevivencia de maíz}

Las semillas y la rizósfera de plántulas de maíz híbrido simple se inocularon independientemente con cada uno de los 100 cultivos de enterobacterias nativas y se determinaron los porcentajes de emergencia y sobrevivencia a los 7 y 20 días respectivamente. Diariamente, hasta 7 días después de la inoculación de las bacterias en las semillas de maíz se contaron las plántulas emergidas, calculándose después el porcentaje de emergencia. 20 días después de la inoculación de las bacterias en la rizósfera, se contaron las plántulas sobrevivientes, para calcular el porcentaje de sobrevivencia.

\section{Resultados y discusión}

En el $100 \%$ (54) de las muestras rizosféricas de maíz, se aislaron bacterias que desarrollaron en agar Mac Conkey, obteniéndose 269 cultivos puros. Entre los
269 cultivos puros de bacterias, $30 \%$ (81) fermentó lactosa y 70\% (188) no la fermentó. En este medio de cultivo también forman colonias un grupo de bacterias no fermentadoras, géneros Burkholderia y Pseudomonas (Cadena y Martínez, 2011; Dávila y Linares, 2013), Cupriavidus necator (Lisboa y Segura, 2010), así como también Acinetobacter y Stenotrophomonas (Juliet y Fernández, 2006; Salazar de Vegas y Nieves, 2011).

A su vez, en el subcultivo realizado, el $51 \%$ (137) resultó oxidasa positivo, el $42 \%$ (120) oxidasa negativo y $4 \%$ (12) no creció. Las bacterias desarrolladas en agar Mac Conkey y que presentaron reacción negativa en la prueba de oxidasa se consideraron enterobacterias, diferenciándose de otras bacterias que también se aíslan en este agar, como Burkholderia, Pseudomonas y Cupriavidus (Lisboa y Segura, 2010; Cadena y Martínez, 2011; Dávila y Linares, 2013), pero que son positivas en la prueba de oxidasa.

El $87 \%$ (104) de las bacterias oxidasa negativas fermentó la glucosa en TSI, siendo considerado como enterobacterias y el $13 \%$ (16) como bacterias no fermentadoras, tal que en el 39\% (21) de las muestras rizosféricas de maíz se aislaron enterobacterias. La fermentación de glucosa en agar hierro triple azúcar permitió separar a otras bacterias como Acinetobacter que es oxidasa negativa, pero no fermentadora. La familia Enterobacteriaceae agrupa bacilos Gram negativas, no esporulados, que carecen de indofenol oxidasa, oxidan y fermentan glucosa, reducen los nitratos a nitritos y se encuentra ampliamente distribuidas en la naturaleza (Puerta y Mateos, 2010).

Se identificaron los géneros Pantoea (49\%), Klebsiella (17\%), Kluyvera (16\%), Serratia (11\%), Citrobacter (4\%) y Hafnia (3\%) (Tabla 1, Figura 1). Entre las bacterias no fermentadoras se identificaron Acinetobacter con $79 \%$ y Stenotrophomonas con $21 \%$. Para la investigación del potencial biológico se seleccionaron 100 cultivos de enterobacterias. 


\section{Tabla 1}

Características diferenciales de los géneros de enterobacterias identificados en suelo rizosférico de Zea mays L. "maíz"

\begin{tabular}{lcccccc}
\hline $\begin{array}{l}\text { Características } \\
\text { diferenciales }\end{array}$ & Pantoea & Hafnia & Kluyvera & klebsiella & Serratia & Citrobacter \\
\hline Fermentación en TSI & K/A & K/A & K/A & A/A & K/A & K/A \\
Gas & \pm & - & & \pm & \pm & + \\
Sulfuro de hidrogeno & - & - & - & - & - & + \\
Utilización de citrato & \pm & \pm & + & + & \pm & \pm \\
Descarboxilación de lisina & - & + & \pm & + & \pm & - \\
Acidez de glucosa en & \pm & \pm & + & \pm & \pm & + \\
caldo & & & & & & \\
Formación de acetoína & + & \pm & - & \pm & \pm & - \\
Producción de indol & \pm & - & \pm & - & \pm & + \\
\hline
\end{tabular}

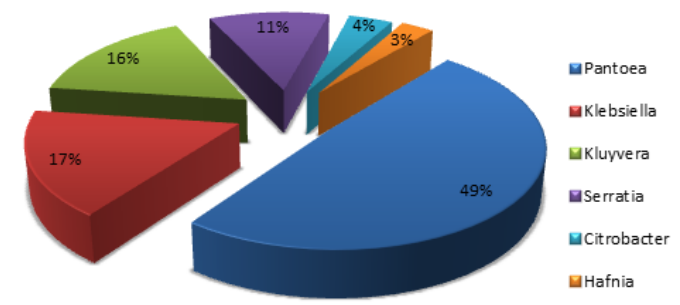

Figura 1. Frecuencia de géneros de enterobacterias aisladas de Zea mays L. "maíz".

\section{Potencial biológico de enterobacterias nativas}

En el $22 \%$ de enterobacterias nativas se detectó actividad proteolítica, evidenciada por la formación de halos alrededor de las colonias (Figura 2), cuyo tamaño osciló entre menos de 2,5 a $4,5 \mathrm{~cm}$ para Klebsiella sp. núm. 89 y Serratia sp. núm. 84 , respectivamente. A su vez, el $25 \%$ de enterobacterias presentó actividad quitinolítica, demostrada por el crecimiento en agar quitina (Figura 3). Según Da Silva et al. (2008), la actividad quitinolítica constituye un mecanismo de biocontrol de hongos fitopatógenos, porque su pared celular está constituida mayoritariamente de polisacáridos como la quitina y glucanos. Por su parte Ogho y Okonkwo (2012), observaron efecto hidrolítico de celulosas y pectinasas en Enterobacter sp., sugiriendo que la actividad enzimática de las rizobacterias les facilita la colonización de las plantas hospedantes.

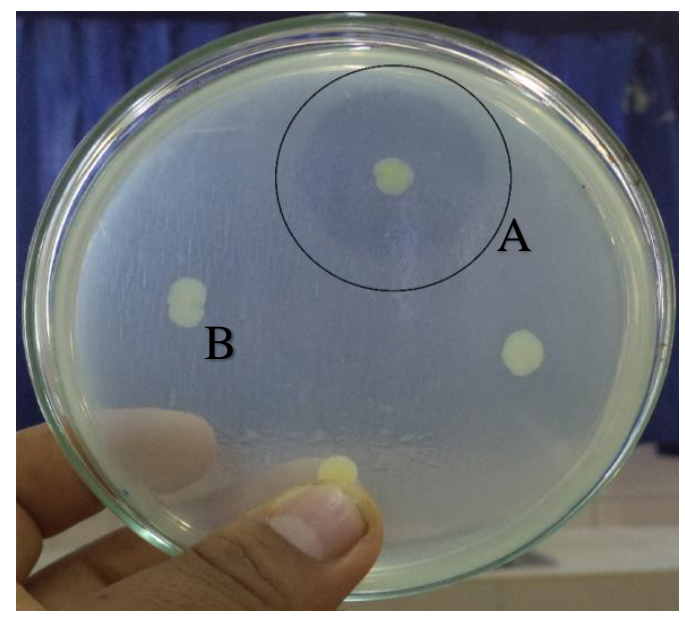

Figura 2. Agar leche cultivado con enterobacterias nativas durante 48 horas. (A) Halo de hidrolisis (zona clara) alrededor de la colonia evidenciando la actividad proteolítica. (B) Colonia sin halo de hidrolisis considerada como no proteolítica.

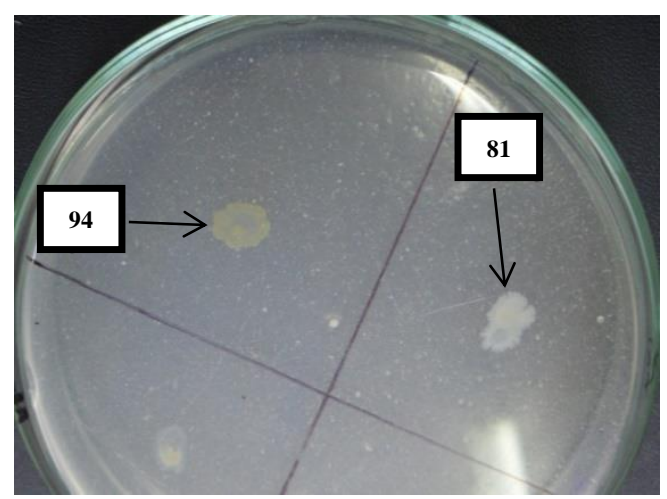

Figura 3. Biomasa formada por enterobacterias nativas, Klebsiella sp. núm. 94 y Klebsiella sp. núm. 81 en agar quitina, consideradas con actividad quinolítica. 
El $97 \%$ de las enterobacterias nativas sintetizaron ácido indolacético, denotado por la aparición de una coloración grosella y se cuantificó entre 0,75 a 54,25 ppm para Klebsiella sp. núm. 5, y Serratia sp. núm. 43, respectivamente. El AIA se cuantificó mediante la reacción colorimétrica de Salkowski, en la que la presencia del indol es directamente proporcional a la intensidad del color grosella observado y a su vez es el resultado de una reacción oxidativa en acidez, donde por una transaminación un grupo amonio del indol es sustituido por el cloro del cloruro férrico (Mantilla, 2007).

El $96 \%$ de las enterobacterias nativas fijaron nitrógeno in vitro evidenciado por la aparición de una película y viraje del indicador al azul y se cuantificó entre 1,16 a 31,67 ppm de amonio para Klebsiella sp. número 94 y Pantoea sp. número 99, respectivamente. Franco (2008) manifestó que la consistencia semisólida del medio $\mathrm{Nfb}$ permite el crecimiento y desplazamiento de las bacterias hacia el lugar, donde la tasa de respiración está en equilibrio con la tasa de difusión del oxígeno y se mantienen las condiciones de microaerofilia requeridas para actividad de la nitrogenasa.

En cuanto a la solubilización de fósforo, el $16 \%$ de enterobacterias nativas solubilizó fosfato dicálcico, observándose viraje del indicador al amarillo y halos translúcidos en agar SRSM, cuyos tamaños oscilaron entre menos de 0,1 a $0,5 \mathrm{~cm}$. En caldo SRSM se cuantificó el fósforo soluble observándose una coloración azul. A su vez, la concentración de fósforo solubilizado osciló entre 4,78 a 1,25 ppm para klebsiella sp. núm. 89 y Pantoea sp. núm. 34, respectivamente. Los medios de cultivo sólidos y líquidos que contienen fosfato insoluble en solución son adecuados para el aislamiento y detección de microorganismos solubilizadores de fósforo. En medios sólidos la positividad está dada por el viraje del indicador al amarillo y la presencia de una zona clara alrededor de las colonias (Vásquez et al.,
2000; Cordero et al., 2008; Carreño, 2009). El principal mecanismo involucrado en la solubilización de fosfatos está relacionado con la síntesis de ácidos orgánicos que producen la acidificación de la célula y su ambiente.

El 95\% de los cultivos de enterobacterias nativas inhibieron el desarrollo de las colonias de Fusarium verticilloides (Figura 4). La inhibición osciló entre 4,2\% a $83,3 \%$ a las 96 horas y $6,3 \%$ a $84,4 \%$ después de 120 horas (Tabla 2). Este hongo es reconocido como fitopatógeno de una variedad de cultivos agrícolas y es el parásito mayoritario de gramíneas, particularmente en las regiones tropicales y subtropicales. Causa quemado de las plántulas, pudrición del tallo y frutos y se puede aislar de semillas (García y Martínez, 2010) y de raíces y tallos infectados (Figueroa et al., 2010).

\section{Tabla 2}

Rango del porcentaje de inhibición del crecimiento de Fusarium verticillioides por enterobacterias nativas

\begin{tabular}{ccc}
\hline Tiempo & \multicolumn{2}{c}{ Rango } \\
\cline { 2 - 3 } (horas) & $\begin{array}{c}\text { Radio colonia } \\
(\mathrm{cm})\end{array}$ & $\begin{array}{c}\text { Inhibición } \\
(\%)\end{array}$ \\
\hline 96 & $2,4-0,4$ & 4,2 \\
120 & $2,9-0,4$ & 6,3 \\
\hline
\end{tabular}

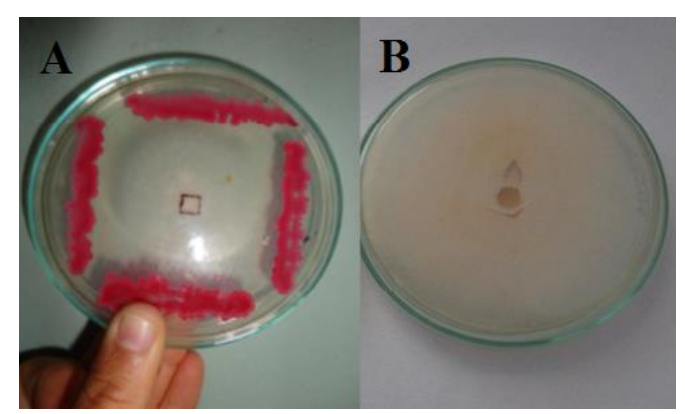

Figura 4. Prueba de Antagonismo de enterobacterias nativas frente a Fusarium verticillioides. (A) Enterobacterias nativas sembradas en agar papa dextrosa para prueba de antagonismo. (B) Fusarium verticilloides desarrollado en agar papa dextrosa. 
Efecto de enterobacterias nativas en la emergencia y sobrevivencia de maíz amarillo duro

Transcurridos 7 días después de la inoculación bacteriana y la siembra de maíz amarillo duro, el $77 \%$ de enterobacterias incrementó la emergencia, alcanzando $80 \%$ a $100 \%$, valores superiores al testigo agua destilada con $50 \%$. Estas bacterias también incrementaron la altura y el vigor de las plantas. Por su parte, el $16 \%$ de enterobacterias nativas no afectó la emergencia, alcanzando valores iguales que el testigo agua destilada (Figura 5). Por el contrario, $7 \%$ de las bacterias nativas disminuyó la emergencia de maíz, presentando valores entre $30 \%$ a $60 \%$. A su vez, transcurridos 20 días después de la inoculación bacteriana en la rizósfera de las plantas de maíz amarillo duro en todos los tratamientos, ninguna bacteria nativa afectó negativamente la sobrevivencia, alcanzando $100 \%$. Las bacterias nativas incrementaron la emergencia de maíz resultado explicado por la activación de procesos metabólicos en las semillas, producto de la secreción bacteriana de sustancias estimuladoras como las giberelinas, encargadas de activar la síntesis de enzimas hidrolíticas en el endospermo (Torres et al., 2013). En este contexto, las $\alpha$ amilasas promueven la germinación, porque incrementan la disponibilidad del almidón (Bharathi et al., 2004).

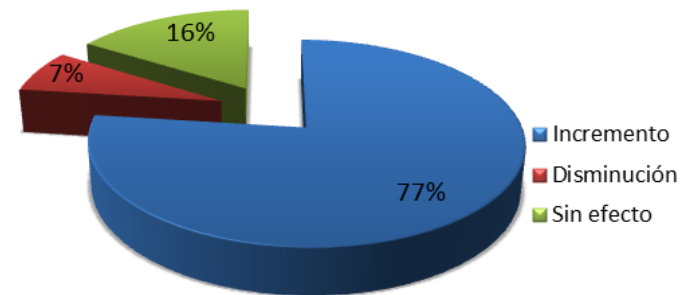

Figura 5. Porcentaje de enterobacterias nativas según el efecto en la emergencia de Zea mays L. "maíz" amarillo duro híbrido a los 7 días.

\section{Conclusiones}

El 100\% de muestras de rizósfera de maíz se identificaron seis géneros de enterobacterias correspondientes a Pantoea
(49\%), Klebsiella (17\%), Kluyvera (16\%), Serratia (11\%), Citrobacter (4\%) y Hafnia (3\%). Con las enterobacterias nativas se cuantificó hasta 31,67 ppm de nitrógeno fijado como amonio; 54,25 ppm de ácido indol acético y 4,78 ppm de fósforo solubilizado, así como también se detectó actividad proteolítica, quitinolítica y antagónica a $F$. verticillioides. El $77 \%$ de enterobacterias nativas aumentó la emergencia de maíz amarillo duro hibrido simple, $16 \%$ no le afectó y $7 \%$ la disminuyó. A su vez, ninguna enterobacteria afectó negativamente la sobrevivencia de plantas de maíz. Demostrándose el potencial promotor del crecimiento vegetal de las enterobacterias aisladas del cultivo de maíz.

\section{Referencias bibliográficas}

Adesemoye, A.; Torbert, H.; Kloepper, J. 2009. Plant growthpromoting rhizobacteria allow reduced application rates of chemical fertilizers. Microbial Ecology 58: 921-929.

Aguado, A.; Moreno, B. 2008. Biofertilizantes bacterianos desarrollados por INIFAP. En Aguado, A, Introducción al uso y manejo de fertilizantes en agricultura. INIFAP/SAGARPA. Guanajuato, México.

Bashan, Y.; Holguin, G.; Ferrera, R. 1996. Interacciones entre plantas y microorganismos benéficos. Terra 14: 159-194.

Bhattacharyya, P.; Jha, D. 2012. Plant growth - promoting rhizobacteria: emergence in agricultura. World Journal Microbiology Biotechnology 28: 1327 - 1350.

Bharathi, R.; Vivekananthan, R.; Harrish, S.; Ramanathan, A.; Samiyappan, R. 2004. Rhizobacteria - based bioformulations for the management of fruit rot infection in chillies. Corp Protection 23: 835-843.

Brenner D.; Krieg. N.; Staley J. 2005. Bergey’s Manual of Systematic Bacteriology: The Proteobacteria, Part B: The Gammaproteobacteria. Springer, USA.

Cadena, S.; Martínez, B. 2011. Caracterización de cepas de Pseudomonas spp. y su efecto en la germinación y emergencia de Zea mays L. "maíz" en Lambayeque. Tesis de Licenciatura. Universidad Nacional Pedro Ruiz Gallo. Lambayeque, Perú.

Carreño, C. 2009. Efecto de la inoculación de bacterias nativas solubilizadoras de fósforo en el desarrollo y rendimiento de tres cultivos agrícolas en Mochumí, Lambayeque, Perú. Tesis de Doctorado. Universidad Nacional de Trujillo. Perú.

Cordero, J.; Ortega, P.; Ortega, E. 2008. La inoculación de plantas con Pantoea sp., bacteria solubilizadora de fosfatos, incrementa la concentración de $\mathrm{P}$ en los tejidos foliares. Revista Colombiana de Biotecnología 10: $111-121$.

Da Silva, C.; Fermino, A.; Da Silva, M. 2008. Caracterização de estreptomicetos com potencial e biocontrole. Scientia Agricola 65: 50-55. 
Dávila, J.; Linares, V. 2013. Especies de Burkholderia y Pseudomonas aisladas de la rizósfera de Jatropha curcas L. pinón blanco y su potencial como promotoras del crecimiento de plantas en Lambayeque, 2012. Tesis de Licenciatura. Universidad Nacional Pedro Ruiz Gallo. Lambayeque, Perú.

Díaz, P.; Ferrera, R., Almaraz, J.; Alcántara, J. 2001. Inoculación de bacterias promotoras del crecimiento en lechuga. Terra 19: 327-335.

Franco, M. 2008. Evaluación de caracteres PGPR en Actinomicetos e Interacciones de esta Rizobacterias con hongos Formadores de Micorrizas. Tesis doctoral. Universidad de Granada. España.

Fernández, O.; Vega, L. 2001. Microorganismos antagonistas para el control fitosanitario. Manejo Integral de Plagas 62: 96- 100.

Figueroa, M.; Rodríguez, R.; Guerrero, B.; González, M.; Pons, J. 2010. Caracterización de especies de Fusarium asociadas a la pudrición de raíz de maíz en Guanajuato, México. Revista Mexicana de Fitopatología 28: 124-134.

García, J.; Mendoza, A.; Mayek, N. 2012. Efecto de Azospirillum brasilense en el rendimiento del maíz en el norte de Tamaulipas, México. Universidad y Ciencia 28: 79-84.

García, F.; Muñoz, H. 2010. Caracterización de cepas nativas de Azospirillum spp. y su efecto como promotor del desarrollo vegetativo de arroz (Oryza sativa). Tesis de Licenciatura. Universidad Nacional Pedro Ruiz Gallo. Lambayeque, Perú.

García, G.; Martínez, R. 2010. Especies de Fusarium en granos de maíz recién cosechados y desgranados en el campo en la región de Ciudad Cerdán, Puebla. Revista Mexicana de Biodiversidad 81: 15-20.

Hernández, R.; Fernández, C.; Baptista, P. 2003. Metodología de la Investigación. Mc Graw Hill Interamericana Editores S.A., México.

Juliet, C.; Fernández, A. 2006. Stenotrophomonas maltophilia. Revista chilena de infectología, 23: 247248.

Kloepper, J. 2003. A review of mechanisms for plant growth promotion by PGPR. 6 th Internacional PGPR workshop. Calicut, India.

Lara, C.; Villalba, M.; Oviedo, L. 2007. Bacterias fijadoras asimbióticas de nitrógeno en la zona agrícola de San Carlos. Revista Colombiana de Biotecnología 9: 6-14.
Lisboa, C.; Segura, S. 2010. Rendimiento de polihidroxialcanoatos de cepas de Cupriavidus necator aisladas de rizósfera de Zea mays "maíz" en Reque, Lambayeque. Tesis de Licenciatura. Universidad Nacional Pedro Ruiz Gallo. Lambayeque, Perú.

Mantilla, M. 2007. Evaluación de la acción de un bioinoculante sobre un cultivo de crisantemo (Chrysanthemun morifolium var. yoko ono) en periodo de enraizamiento. Tesis Microbiólogo Agrícola Veterinario. Pontificia Universidad Javeriana. Bogotá, Colombia.

Municipalidad Distrital de Monsefú. 2013. Disponible en: http://munimonsefu.gob.pe/

Municipalidad Distrital de Reque. 2013. Disponible en: ales/Municipalidades/1244/entidad/pm_municipalidad. asp.

Nicolalde, A.; Quintana, D. 2010. Utilización de bacterias fijadoras de nitrógeno (Azotobacter) y solubilzadoras de fósforo en el cultivo de brócoli (Brassica oleraceae var. Legacy) en Otavalo. Universidad Técnica del Norte. Ecuador.

Ogho, F.; Okokwo, J. 2012. Some Characteristics of a plant growth promoting Enterobacter sp. isolated from roots of maize. Advances in Microbiology 2: 368-374.

Puerta, A.; Mateos, F. 2010. Enterobacterias. Medicine 10: 3426-3431.

Ríos, P.; Zúñiga, L. 2012. Bacillus spp. aisladas de rizósfera de Lycopersicon esculentum Mill. "tomate" en Lambayeque y su potencial coimo promotoras del crecimiento de plantas. Tesis de Licenciatura. Universidad Nacional Pedro Ruiz Gallo. Lambayeque, Perú.

Rodier, J.; Rodi, L. 2005. Análisis de Aguas. Ediciones Omega, España.

Salazar de Vegas, E.; Nieves, B. 2011. Acinetobacter spp. Aspectos microbiológicos, clínicos y epidemiológicos. Revista de la Sociedad Venezolana de Microbiología 25: 64-71.

Torres, R.; Perez, C.; Suárez, N. 2013. Influencia de la inoculación de rizobacterias sobre la germinación de semillas de frejol común (Phaseolus vulgarid L.). Centro Agricola 30: 56-60.

Vázquez, P.; Holguin, G.; Puente, M.; López, A.; Bashan, Y. 2000. Phosphate solubilizing microorganisms associated with the rhizosphere of mangroves in a semiarid coastal lagoon. Biology and Fertility of Soils 30: 400-408. 